\title{
Innovative Framework for e-Government adoption in Saudi Arabia: A Study from the business sector perspective
}

\author{
Saleh Alghamdi \\ School of Engineering and Informatics \\ Informatics Department \\ University of Sussex \\ Brighton, UK
}

\author{
Natalia Beloff \\ School of Engineering and Informatics \\ Informatics Department \\ University of Sussex \\ Brighton, UK
}

\begin{abstract}
E-Government increases transparency and improves communication between the government and the users. Providing e-Government services to business sector is a fundamental mission of governmental agencies in Saudi Arabia. However, the adoption of e-Government systems is less than satisfactory in many countries, particularly in developing countries. This is a significant factor that can lead to e-Government failure and, therefore, to the waste of budget and effort. One pertinent, unanswered question is what are the key factors that influence the adoption and utilisation level of users from business sector. Unlike much research in the literature that has utilised common technology acceptance models and theories to analyse the adoption of e-Government, which may not be sufficient for such analysis, this study proposes a conceptual framework following a holistic approach to analyse key factors that influence the adoption and utilisation of e-Government in Saudi Arabia. The developed framework, E-Government Adoption and Utilisation Model (EGAUM), was developed based on critical evaluation of several common models and theories related to technology acceptance and use including Technology Acceptance Model (TAM) and Unified Theory of Acceptance and Use of Technology (UTAUT), in conjunction with analysis of e-Government adoption literature. The study involved 48 participating business entities from two major cities in Saudi Arabia, Riyadh and Jeddah. The descriptive and statistical analyses are presented in this paper and the results indicated that all the proposed factors have degree of influence on the adoption and utilisation level. Perceived Benefits, Awareness, Previous Experience, and Regulations \& Policies were found to be the significant factors that are most likely to influence the adoption and usage level of users from business sector.
\end{abstract}

Keywords-E-Government; E-Services; Saudi Arabia; Technology Adoption; Influential Factors; Users' Intention; Business Sector Perspective

\section{INTRODUCTION}

Information and Communication Technologies (ICTs) are considered to be the backbone of many activities used nowadays. They have a considerable potential to provide solutions and to solve problems in different aspects, which then lead to enhanced quality of life. Given the fact that the accelerated development of Information Technologies (ITs) has led to a rapid increase in the number of websites and services provided by governments, nearly all governments of countries around the world have at least a web presence, or so-called e-
Government [1]. Currently, the role of ICTs is crucial in governance processes, where they can help to create a structured network for service delivery [2], effectiveness and efficiency [3], interactivity, accountability and transparency [4].

E-Government refers to the utilisation of various Information and Communication Technologies (ICTs) for facilitating communication between the government and the stakeholders; citizens, businesses and governmental agencies, providing effective, efficient and integrated e-Services that enhance the interaction between the government and the stakeholders through multiple and flexible channels that lead to an increased engagement. E-Government initiatives are still in the early stages in most developing countries, and face many issues related to adoption, implementation and utilisation. Adoption and utilisation level is fundamental in terms of measuring the success in the implementation of e-Government systems. While governments develop e-Government systems to provide e-Services to different stakeholders, the adoption and usage level is still low especially in developing countries [5][6][7]. Successful implementation of ICTs in government processes and satisfactory usage level by all government stakeholders are the main goals of e-Government. Thus, analysing the significant factors that influence the adoption and utilisation of e-Government becoming a necessity. This study focused on exploring determinants and factors that would contribute to the increase of users' adoption and use and also to the success of e-Government systems implementation.

One of the main targeted stakeholders when providing eGovernment services is business sector. Business sector, or what so called private sector in Saudi Arabia, is growing considerably in the recent years. The growth rate of the private sector is the highest between the three main sectors in Saudi Arabia, namely, governmental sector, private sector and oil sector [8]. Therefore, facilitating the communication and interaction between government agencies and business sector (business firms) is very important especially in the current advanced IT era. Many online e-Services have been provided to the private sector in the recent years in Saudi Arabia and there are more e-Services under development. Besides the need to increase the adoption and utilisation level of the implemented e-Government systems, it is also crucial to understand the 
factors that can influence the adoption and usage of the new eServices. The analysis of such factors will bring e-Government service provided to business sector to a more successful level and also will draw the path for developing new e-Government services.

In order to explore and understand the determinant factors of high adoption and usage level of e-Government, we need to utilise a comprehensive framework. Thus, this paper developed a conceptual framework for this purpose, namely, E-Government Adoption and Utilisation Model (EGAUM). Early stages of the development process of this model was presented at Federated Conference on Computer Science and Information Systems, see [9]. The rest of this paper will be divided as follows: the second section highlights the essentials of the research model and the third section will present the study methodology. The fourth section will present and discuss the findings including the descriptive and statistical analysis whereas a conclusion will be presented in the fifth section.

\section{THE PROPOSED RESEARCH MODEL (EGAUM)}

In order to explore and analyse key factors that influence e-Government adoption and utilisation from business sector perspective, this study developed a comprehensive model we called the E-Government Adoption and Utilisation Model (EGAUM). This model provides a holistic framework to analyse key factors that have crucial influence on the adoption and diffusion of e-Government. EGAUM was developed based on critical analysis of the literature on e-Government adoption, in conjunction with insights from several models and theories that are commonly used to analyse the acceptance and usage of technologies including the Theory of Reasoned Action (TRA), the Technology Acceptance Model (TAM), the Diffusion of Innovation Theory (DOI), Perceived Characteristics Innovation (PCI) and the Unified Theory of Acceptance and Use of Technology (UTAUT) [10][11][12][13][14]. The main goal of the proposed model (EGAUM) is to determine factors that could influence the users' beliefs and intentions, as well as the behaviour that influence their adoption and usage levels. In the development of EGAUM, several significant constructs were integrated from well-studied frameworks such as Perceived Benefits, Perceived Simplicity and Social influence whereas several other constructs were introduced and developed specifically for EGAUM [9].

The EGAUM model consists of two dependent variables, namely Intention to Use E-Government (ITU) and Perceived E-Readiness of e-Government (PER) which lead to the Actual Adoption and Utilisation of e-Government. EGAUM also contains four groups of independent variables, which are Personal Factors, Motivational Factors, Technical Factors and Reliability Factors. These independent variables represent the fundamental groups of factors that have a critical influence on the adoption and usage levels of e-Government. The EGovernment Adoption and Utilisation Model (EGAUM) is shown in Fig. 1. Detailed information about its developing process and its constructs is presented and published in [9].

\section{THE RESEARCH METHODOLOGY}

The study surveyed 53 business entities from different cities in Saudi Arabia, namely, Riyadh and Jeddah. Most of

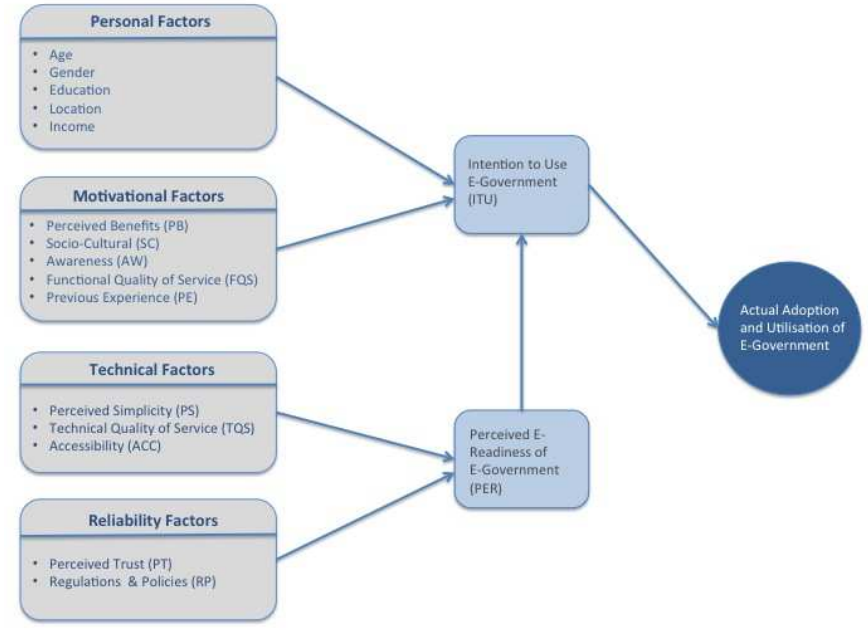

Fig. 1: E-Government Adoption and Utilisation Model (EGAUM) [9].

them were leader and large companies. Several medium and small business entities have also been involved in this study sample. The data has been collected in the period between August and October 2014. The business activities of the participating companies were different in order to provide more comprehensive results. The sample included both business owners and employees who work in business firms and deal with government agencies with regard to their companies' transactions. Incomplete questionnaires were also excluded since all the questionnaires' items need to be answered as they represent the research model constructs. Therefore, the total valid responses were from 48 business entities.

A 99-item questionnaire was distributed to the participants to respond to. The questionnaire comprised different forms of questions including 5-points Likert scale and 5-points importance degree questions. Although the questionnaire was relatively long, it collected fundamental data that led to efficient and sufficient analysis. The questionnaire was distributed in person for several reasons. For example, users from business sector are usually busy and it is likely that they would not response completely to questionnaires. Thus, meeting them in person at their appropriate time would ensure high response rate. Moreover, meeting such participants in person would help to clarify questions when they need. The data has been collected from different cities in Saudi Arabia. Although this way consumed effort, cost and time, it enabled us to obtain more comprehensive and useful data.

Since the factors in the research model (EGAUM) are abstract [9], number of items was developed for each factor to measure its influence on the adoption of e-Government. Raubenheimer stated that number of items per factor is crucial specifically for scales with one factor which requires at least four items to be identified. However, most of the scales measure more than one factor. Scales that measure more than one factor, like this research scale, can be identified with as little as two items [15]. Table 2 shows the number of items for each factor in the scale developed for this study. 
TABLE 2: Demographic data [21]

In terms of validity and reliability of the study instrument, Blunch stated that a research instrument is evaluated by its reliability. The reliability of a measuring instrument means its ability to provide identical results if it is repeated under identical conditions [16]. This study used the internal consistency method to test the reliability with the use of Cronbach's Alpha, see Table 1. With regards to the instrument's validity, Bhattacharyya defined validity as "the degree to which a test measures what it intends to measure" [17]. Validity of an instrument does not mean that the instrument is either valid or not but it is a matter of degree. The greater the evidence that an instrument produces valid results the greater the likelihood that we will get information that we need [18]. Validity cannot be calculated or measured directly, it is judged by the existing evidence [19]. This study utilised face validity and content validity methods to evaluate its validity degree. Face Validity method provides useful information about the measure instrument and determines to what extent the instrument meets the intended purpose [18]. Test in which its purpose is clear, even for simple persons who have elementary knowledge, is judged to have high face validity. Where on the other hand, test in which its purpose is unclear would be judged to have low face validity [20]. Most of the items developed in this study were accurately face validated during the pilot study phase by the participants in accordance to the model factors' purposes, whereas some of them were not validated due to lack of understanding them clearly. Invalid items were either reworded if they were reported as unclear or deleted if they were reported as irrelevant. Furthermore, 5 academic members who are experts in interactive systems field have also reviewed the research instrument to have high content validity. Thus, it has been reviewed, tested and revised several times in order to have high validity.

\section{RESEARCH FINDINGS AND DISCUSSION}

This section provides an overview of the demographic characteristics of the respondents including age groups, education level, income, the use of the Internet and the use of eGovernment systems. This is followed by a brief descriptive analysis of each factor as well as the statistical analysis of the collected data which explains the correlation between the model's constructs that led to the hypotheses fit. For more details about the descriptive analysis see [21].

TABLE 1: Internal consistency of the study instrument [21]

\begin{tabular}{lcc}
\hline Measured variable & \# of items & Cronbach's $\alpha$ \\
\hline Perceived Benefits (PB) & 7 items & .825 \\
Socio-Cultural (SC) & 5 items & .686 \\
Awareness (AW) & 9 items & .822 \\
Functional Quality of Services (FQS) & 10 items & .800 \\
Previous Experience (PE) & 3 items & .601 \\
Perceived Simplicity (PS) & 6 items & .638 \\
Technical Quality of Service (TQS) & 5 items & .624 \\
Accessibility (ACC) & 4 items & .619 \\
Perceived Trust (PT) & 9 items & .792 \\
Regulations and Policies (RP) & 4 items & .899 \\
Intention to use e-Government (ITU) & 2 items & .659 \\
Perceived e-Readiness of e-Government (PER) & 2 items & .667 \\
\hline
\end{tabular}

\begin{tabular}{|c|c|}
\hline Variables & $\%$ \\
\hline \multicolumn{2}{|l|}{ Participants gender } \\
\hline Male & 89.6 \\
\hline Female & 10.4 \\
\hline \multicolumn{2}{|l|}{ Participants age in years } \\
\hline $18-30$ & 20.8 \\
\hline $31-45$ & 64.6 \\
\hline $46-60$ & 12.5 \\
\hline Over 60 & 2.1 \\
\hline \multicolumn{2}{|l|}{ Participants education level } \\
\hline Secondary school or less & 29.2 \\
\hline Diploma & 20.8 \\
\hline Bachelor degree & 41.7 \\
\hline Master & 8.3 \\
\hline \multicolumn{2}{|l|}{ Proficiency of using computer } \\
\hline Average & 8.3 \\
\hline Good & 41.7 \\
\hline Excellent & 50 \\
\hline \multicolumn{2}{|l|}{ Internet usage rate } \\
\hline Several days a week & 6.3 \\
\hline Several days a month & 2.1 \\
\hline Everyday & 91.6 \\
\hline \multicolumn{2}{|c|}{ Participants relationship to the business } \\
\hline Owner & 27.1 \\
\hline Representative & 18.8 \\
\hline Employee & 54.2 \\
\hline \multicolumn{2}{|l|}{ Business age in years } \\
\hline $0-5$ & 16.7 \\
\hline $6-10$ & 16.7 \\
\hline $11-20$ & 10.4 \\
\hline Over 20 & 56.3 \\
\hline \multicolumn{2}{|c|}{ Number of employees in business } \\
\hline $0-10$ & 18.8 \\
\hline $11-50$ & 8.3 \\
\hline $51-250$ & 4.2 \\
\hline More than 250 & 68.8 \\
\hline \multicolumn{2}{|c|}{ Annual net profit in SAR $(1 \mathrm{GBP} \approx 5.7)$ SAR } \\
\hline $0-60000$ & 10.4 \\
\hline $61000-12000$ & 4.2 \\
\hline $121000-180000$ & 2.1 \\
\hline $181000-240000$ & 4.2 \\
\hline More than 240000 & 35.4 \\
\hline Unknown & 43.8 \\
\hline \multicolumn{2}{|l|}{ Business field } \\
\hline Constructing and building & 14.6 \\
\hline Restaurants & 2.1 \\
\hline Food supply and grocery & 4.2 \\
\hline Cars trade (sale and lease) & 12.5 \\
\hline Communication & 6.3 \\
\hline Health and medical supply & 14.6 \\
\hline Other & 45.8 \\
\hline
\end{tabular}

\section{A. Respondents' demographic data}

This section presents the demographic data obtained from the respondents (see Table 2). As per the questionnaire results, the average age group was ranging between 31 and 45 with males accounting for $89.5 \%$ of the participants and $10.4 \%$ were female. It is clear that the percentage of male participants was more than female participants. These percentages were expected for several reasons. Most of the employees who work in business sector (private sector) and use e-Government services in their jobs' activities are male employees. This is mainly because of the jobs that involve dealing with government agencies to perform governmental transactions were almost exclusive to men before implementing e-Government in Saudi Arabia, therefore, they dominate these kinds of jobs due to their experience of dealing with the government services. Furthermore, it is difficult to collect data in person from female in Saudi Arabia, either business owners or employees, due to religious and cultural reasons. 
TABLE 3: The most significant factors.

\begin{tabular}{llll}
\hline $\begin{array}{l}\text { Hypothesised } \\
\text { relationship }\end{array}$ & $\begin{array}{l}\text { Direction of } \\
\text { relationship }\end{array}$ & $\begin{array}{l}\text { Hypothesis } \\
\text { test }\end{array}$ & $\begin{array}{l}\text { Relationship } \\
{[\mathbf{4 2}]}\end{array}$ \\
\hline $\mathrm{PB} \rightarrow \mathrm{ITU}$ & Positive & Supported & Strong $\left(r_{s}=.543^{* *}\right) \mathrm{Sig}$ \\
\hline $\mathrm{AW} \rightarrow \mathrm{ITU}$ & Positive & Supported & Medium $\left(r_{s}=.463^{* *}\right) \mathrm{Sig}$ \\
\hline $\mathrm{PE} \rightarrow \mathrm{ITU}$ & Positive & Supported & Medium $\left(r_{s}=.354^{*}\right) \mathrm{Sig}$ \\
\hline $\mathrm{RP} \rightarrow \mathrm{PER}$ & Positive & Supported & Medium $\left(r_{s}=.402^{* *}\right) \mathrm{Sig}$ \\
\hline *. Correlation is significant at the 0.05 level. **. Correlation is significant at the 0.01 level.
\end{tabular}

\section{B. Data analysis and hypotheses fit}

In this section, the statistical analysis of the collected data will be presented alongside with brief about the descriptive analysis. The findings will be investigated in order to test the acceptance/rejection of the research hypothesis. Moreover, the correlation between the independent and dependant variables will be investigated. The results indicated that 4 factors found to be the most significant factors that are very likely to influence the adoption and utilisation of users from business sector. These factors were Perceived Benefits, Awareness, Previous Experience and Regulations \& Policies (see Table 3).

\section{Perceived Benefits $(P B)$}

The Likert score of $P B$ factor obtained from the descriptive analysis was $(M=1.37)$ indicating that this factor is very likely to influence the adoption and utilisation of users from business sector. The analysis of all $P B$ items revealed that such factor would increase the intention to adopt and use e-Government services provided to the business sector [21]. This result supports the hypothesised relationship between the Perceived Benefits factor and the Intention to Use e-Government systems.

H1: There would be a positive relationship between perceived benefits and intentions to use e-government services.

The results suggest that the intention to use e-Government services is very likely to increase if users from business sector perceive the e-Services to be beneficial for their businesses. This indicates that to get business owners and business representatives to adopt and use e-Government services, these services must be useful for their business. Such e-Services should be implemented efficiently and effectively in order to meet the needs of this category of stakeholders.

The relationship between the two variables, namely, Perceived Benefits factor and Intention to Use has been assessed statistically. Spearman's correlation procedure was run to assess the relationship between PB and ITU and the results showed that the there is a strong positive correlation between $P B$ and $I T U, \mathrm{r}_{\mathrm{s}}=.543, \mathrm{n}=48, p<.0005$, with high level of perceived benefits associated with high level of intention to use e-Government. In other word, as the users from business sector perceive the benefits that they can gain from using eGovernment systems, they are very likely adopt and use them for their businesses' transactions. Fig. 2 shows the linear trend line that represents the positive relationship between the two variables.

The findings from this factor results are in accordance with other studies' results reported in the literature. Carter and Belanger have conducted a study to understand factors that influence the adoption of e-Government. They found that users' intention to use e-Government services would increase

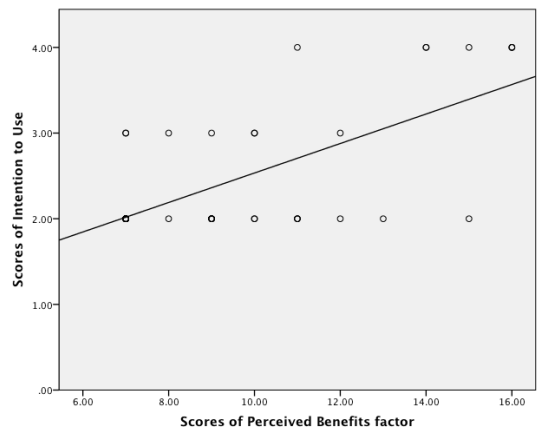

Fig. 2: The relationship between PB factor and ITU.

if they perceive the e-Services to be useful [22]. Moreover, Dimitrova and Chen conducted a study to examine nondemographic characteristics on the adoption of e-Government. One of their key findings was that the perceived usefulness would be positively related to e-Government adoption. They suggested that choosing to adopt e-Government services is rooted in the perceived benefits of using such e-Services [23]. Rogers in his Diffusion of Innovation theory also suggested that the benefits perception of using an innovation has a positive influence on the adoption decision [24].

Furthermore, AlAwadi and Morris have studied the factors that influence the adoption of e-Government services in Kuwait which is a close neighbour country to Saudi Arabia that have similar nature and culture. They found that if the users perceive e-Government services to be beneficial and useful, their intention to use such e-Service is likely to increase. They suggested that to get users to adopt and use e-Government services, these e-Services must be genuinely beneficial for them, such e-Services should be implemented effectively to satisfy their users [25]. This suggestion is emphasised when providing online governmental services to business sector where its users require high volume of transactions and services.

Businesses entities are normally required to perform many transactions that are provided by government agencies. Obtaining commercial permeations, applying for importing goods certificates and completing workers' paperwork are examples of many activities that users from business sector need to complete. An additional method of doing these tasks, the Internet, is a very useful method. Since increasing users' perception of benefits increases their intention to use eGovernment services, government agencies should disseminate the benefits and advantages of using such online services and also present the potentials of implementing such e-Services. Government organisations should play a proactive role in popularizing the benefits of online government e-Services to the users from business sector. An understanding of the eGovernment potentials and its benefits to the business sector will increase users intention to adopt and use it.

\section{Socio-Cultural (SC)}

The Likert score of $S C$ factor obtained from its descriptive analysis indicated an impact of $S C$ on the intention to adopt and use e-Government services. Although the Likert score of 2.44 that was obtained from the descriptive analysis did not represent a high influence level, it gave us an indication of a possible positive effect of this factor on users from business 


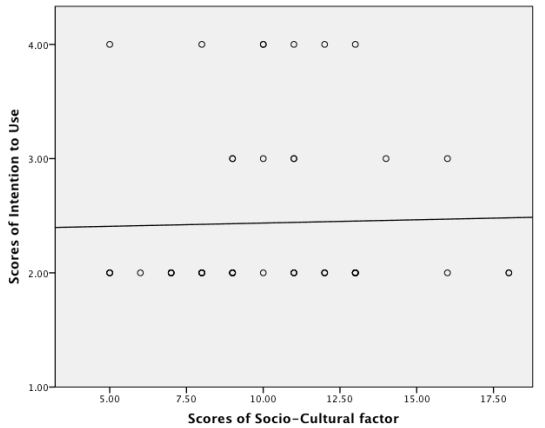

Fig. 3: The relationship between SC factor and ITU.

sector [21]. It is likely that users' intention to adopt and use e-Government would not be influenced much by the social and cultural aspects.

The relationship between Socio-Cultural factor and Intention to Use was investigated using Spearman's correlation coefficient. The results indicated that there is a positive relationship between $S C$ and $I T U, \mathrm{r}_{\mathrm{s}}=.098, \mathrm{n}=48, p>.05$. Fig. 3 shows the linear trend of this relationship. Although the relationship between $S C$ and $I T U$ is considered to be weak, the result of the correlation coefficient shows a positive influence of the Socio-Cultural factor. The findings from the descriptive analysis of this factor as well as the correlation result supports the hypothesised relationship between SC and ITU.

H2: There would be a positive relationship between SocioCultural influence and intentions to use e-government services.

We can conclude that the social and cultural aspects do not significantly influence the adoption and utilisation of users from business sector when using e-Government services for their businesses' transactions. This is likely because they are practical users more than other users due to the busy environment that they work in. In other word, users from business sector normally need to perform a lot of governmental transactions and also need to obtain many services for heir business entities regardless any other external factors such as the social life or the society culture. The influence of the Socio-Cultural factor on the intention to use e-Government services was not supported in several studies in the literature. For example, Alshehri et al. found that social influence do not have a significant effect on intention to use e-Government services [26]. Moreover, AlAwadi and Morris found that social influence was not significant to many participants in their study [25]. As stated earlier that users from business sector might not affected much by the social and cultural norms due to their high desire for online government services.

\section{Awareness (AW)}

Two groups of items were involved in $A W$ measurement, namely, $A W$ part1 and $A W$ part2. The descriptive analysis revealed that it is likely that Awareness would positively influence the adoption and usage level of users from business sector. The Likert score of some items showed a significant influence of such factor. For example, the vast majority of the respondents agreed on that offering awareness campaigns would encourage them to attend to know more about eGovernment potentials and benefits and this would positively

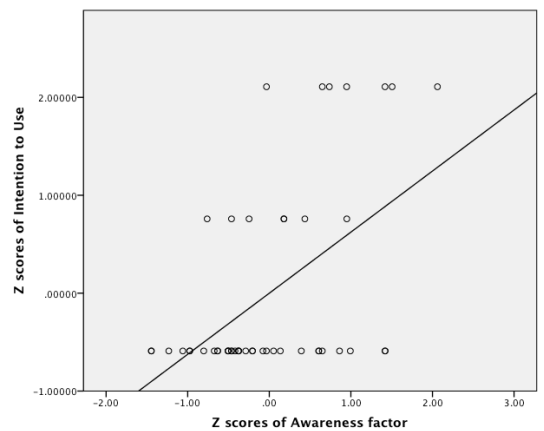

Fig. 4: The relationship between AW factor and ITU.

influence their adoption and utilisation [21].

With regard to the statistical analysis, the correlation between $A W$ and ITU was assessed using Spearman's correlation procedure and the results revealed that there is a relatively strong relationship between them, $\mathrm{r}_{\mathrm{s}}=.46, \mathrm{n}=48, p<.0005$. Fig. 4 shows the positive correlation trend line between $A W$ and $I T U$. We can conclude from the descriptive analysis and the correlation assessment that the Awareness factor positively influences the adoption and utilisation of users from business sector. The findings support the hypothesised relationship between Awareness and Intention to Use.

\section{H3: There would be a positive relationship between awareness} and intentions to use e-government services.

These findings are similar to those reported in Al-Awadi and Morris study where they found that Awareness plays a vital role in the use of e-Government [25]. Moreover, Alshihi in his study also found that users' awareness about e-Government correlate positively with the willingness to use e-Government [27]. Baker and Bellordre stated that lack of awareness, that a given technology is exist or that it could of benefits, is a primary concern associated with the diffusion and use of technologies in general [28]. This is emphasised in the case of diffusion, adoption and utilisation of e-Government systems, as they are national and multi users systems.

Sufficient and efficient awareness campaigns are needed to achieve high level of adoption and usage of e-Government services. This is even more important for e-Services provided to business sector as they have large volumes of governmental transactions need to be completed. Increasing the awareness of the benefits and potentials of using e-Government services would significantly decrease the loads on the government agencies as customers from business sector would be encouraged to use online services rather than visiting agencies.

\section{Functional Quality of Service (FQS)}

The influence of $F Q S$ was also measured with two groups of items, namely, FQS part1 and FQS part2. The Functional Quality of Service refers to the external functional aspects that affect on the quality of the provided e-Service such as payment methods and the correspondence methods of the required documents. The Likert scores of the descriptive analysis of the two parts were 2.21 and 1.74 respectively. The descriptive analysis results revealed a positive impact of the high quality of the functional aspects on the users' adoption and use [21]. 


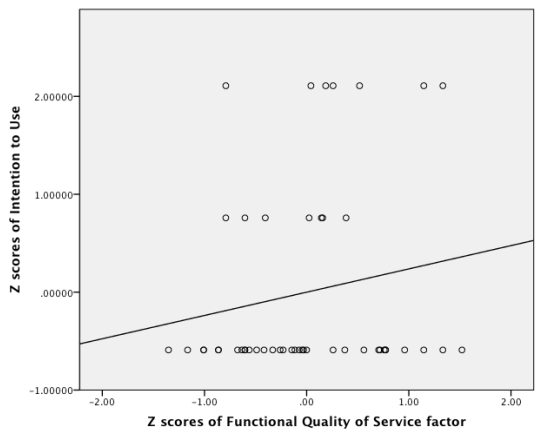

Fig. 5: The relationship between FQS factor and ITU.

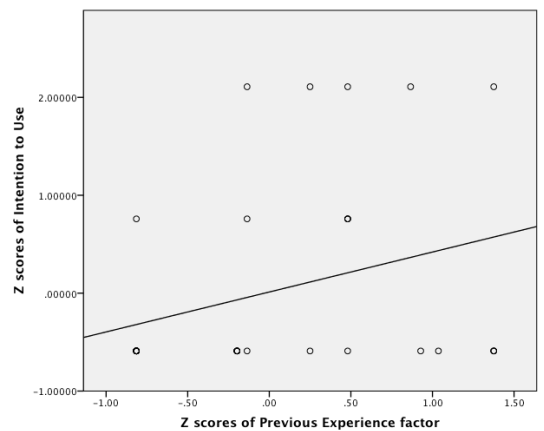

Fig. 6: The relationship between PE factor and ITU.
In terms of assessing the correlation between Functional Quality of Service factor and Intention to Use, Spearman's correlation coefficient was utilised. The result of the correlation test showed a positive relationship between FQS and ITU although the correlation was weak, $\mathrm{r}_{\mathrm{s}}=.165, \mathrm{n}=48, p>.05$. Fig. 5 shows the correlation trend line between both variables. The findings of both the descriptive analysis and correlation assessment can be summarised as that $F Q S$ positively influence the adoption and utilisation of users from business sector. This means the higher functional quality of e-Service it is, the more users from business sector will intend to adopt and use e-Government services. Thus, the hypothesised relationship between FQS and ITU was supported.

H4: There would be a positive relationship between functional quality of service and intentions to use e-government services.

E-Government should provide high quality services and also high quality delivery processes [29]. The finding of this factor is in accordance with those reported Abdelsalam et al. and Elkadi studies study. They found that service quality positively affects the use of e-Government [30][31]. Rehman et al. also found that the quality of e-Government services significantly influences the intention to perform transactions with e-Government [32]. In the current study, the influence of this factor was not found to be significant as in the discussed studies but it found a positive impact as they found. This is likely because those studies have been conducted with different e-Government stakeholders, employees in the former and citizens in the later. This means that FQS has less impact, on users from business sector, than public users or employees.

\section{Previous Experience (PE)}

$P E$ was measured with three items with three different scales based on the question goal. All the three items were dependent on other prior items in the questionnaire and they measured the possible influence of the previous experience of using governmental online services and also the previous experience of using non-governmental online services such as online banking and online purchases. All of $P E$ items were analysed separately in the descriptive analysis and the results indicated a high likelihood that the previous experience of using online services would significantly influence the intention to use eGovernment services [21]. In order to statistically analyse the relationship between $P E$ and ITU, Spearman's correlation coefficient was produced. The correlation between the Previous Experience factor and Intention to Use for the respondents who have used different kinds of e-Services, either governmental and non-governmental, found to be positive and significant $r_{s}$ $=.354, \mathrm{n}=33, p<.0005$. Thus, the following hypothesised relationship between $P E$ and $I T U$ is supported. Fig. 6 shows the relationship trend line between both variables.

H5: There would be a positive relationship between previous experience and intentions to use e-government services.

The previous experience is important in terms of using online e-Services. It can either encourage or discourage users to use such e-Services in the future. In other word, previous experience can predict and determine the users' intention to use online services. This is because different perceptions are likely built based on the previous experience. These perceptions include trust perception, ease of use perception and usefulness perception. AlAwadi and Morris found in their research that number of participant held negative view of e-Government due to negative previous experience. Those participants reported that such negative experience would deter them from using such e-Services in the future. They also found that trust in e-Commerce would lead to trust in e-Government [25]. This means that trust perception gained from previous experience of using e-Commerce would influence the trust perception when using e-Government. The importance of the previous experience was also supported in the descriptive analysis in this research.

\section{Perceived Simplicity (PS)}

$P S$ factor was also measured with two groups of items and two different scales [21]. The relationship between $P S$ and $I T U$ was indirect through Perceived E-Readiness (PER). Therefore, the relationship between Perceived Simplicity $(P S)$ and Perceived E-Readiness (PER) was investigated using Spearman's correlation coefficient. There was a weak but positive correlation between the two variables, $\mathrm{r}_{\mathrm{s}}=.195, \mathrm{n}=48, p>.05$. Although the correlation was not strong, the result shows a positive relationship that indicates high level of perceived simplicity is associated with high level of perceived e-Readiness. Thus, the results supported the hypothesised relationship.

H6: There would be a positive relationship between perceived simplicity and perceived e-Readiness of e-Government.

Besides the results from the statistical analysis, the descriptive analysis showed similar results of the positive influence of $P S$. The results obtained from the descriptive analysis of $P S$ factor can be interpreted as that the $P S$ is an influential factor that positively affect the adoption and utilisation of users from business sector. 


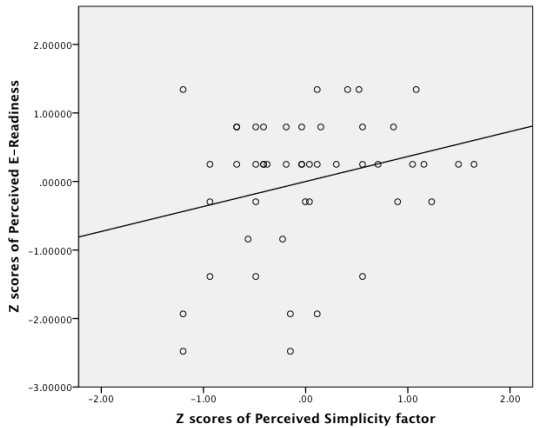

Fig. 7: The relationship between PS factor and PER.

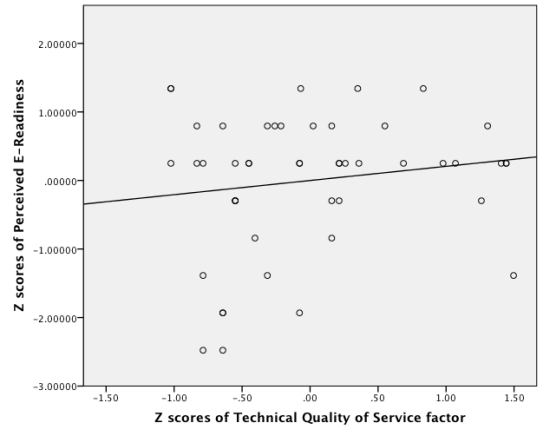

Fig. 8: The relationship between TQS factor and PER.
Although Perceived Simplicity factor was not found to be significant and the correlation between PS and PER was weak, a positively association was found between both of them. Fig. 7 presents the relationship trend line between Perceived Simplicity when using e-Government and Perceived E-Readiness of eGovernment. Since the majority of the participants were from large business entities (around 70\%) where they likely perform large amount of e-Services and e-Transactions and also most of them had a very good Internet experience $(91 \%$ daily Internet users), the simplicity factor was expected not to be a significant factor due to the experience of daily usage of Internet and online services [21]. AlAwadi and Morris suggested in their research work that the greater one's use Internet experience, the easier it would be to learn and use e-Government services [25]. Moreover, Carter and Belanger found that ease of use, which is similar to simplicity in the current research, were not significant in the intention to use e-Government of users with Internet experience [22]. However, e-Government services need to be straightforward and simple to use in order to enable all potential users, either with high or low experience, to benefit from such e-Services. This simplicity is emphasised when it comes to providing e-Services to business sector where large number of e-Services and e-Transactions are involved.

\section{Technical Quality of Service (TQS)}

Two groups of items were involved in the measurement of TQS factor. The results from the descriptive analysis of both parts indicated that $T Q S$ is an influential factor. It did not reveal a significant effect but it gave an indication that there is a positive influence on the adoption and utilisation level [21].

In terms of statistical analysis, Spearman's correlation procedure was utilised to assess the relationship between $T Q S$ and PER. It was found that there is a weak relationship between the two variables, $\mathrm{r}_{\mathrm{s}}=.108, \mathrm{n}=48, p>.05$. However, the relationship was positive which means high level of technical quality of service positively influence the perceived e-Readiness of e-Government. Although the correlation was weak, the result supported the positive hypothesised relationship between the Technical Quality of Service and eReadiness perception. The relationship trend line is shown in the scatterplot graph presented in Fig. 8 .

H7: There would be a positive relationship between technical quality of service and perceived e-Readiness of e-Government.

Technical aspects in e-Government systems are crucial in terms of judging the quality of service especially when they are visible to the users such as interface design and website errors. Moreover, the technical features that reflect the quality of service such as the expected time to complete the e-Transactions and the last update time of the required procedures are also significant. A high quality of the technical side including the design, structure and layout of e-Government portals is needed for the successful adoption and utilisation [33]. Technical issues in e-Government systems might interrupt service transactions and processing performance which can cause severe delay in all governmental agency work and then low adoption and utilisation [25]. Several studies in the literature found that the quality of technical aspects are crucial and has significant impact on the usage level. For example, Alshehri et al. found that website quality, which is one of the technical aspects, directly impacts usage behaviour of eGovernment. Their study confirmed the importance of quality government websites as one of the significant factors of eGovernment adoption [34].

Nevertheless, the findings show no significant impact of the Technical Quality of Service on the E-Readiness perception of users from business sector. This indicates that TQS is not a fundamental factor that determines their adoption and utilisation but this does not diminish the positive influence of high technical quality. Although these technical and visible aspects were reported as an important in the descriptive analysis, they found to be not significant in the statistical analysis. This is possibly because the majority of the participants were employees in the participating business entities (81\%) and they likely did not consider the technical aspects measured in this research as a fundamental factor that influences their adoption and utilisation of e-Government services [21]. These technical aspects might be more important for other e-Government users but not the users from business sector.

\section{Accessibility (ACC)}

The measurement of the influence of Accessibility (ACC) factor consisted of two groups of items with two different scales. The influence of different aspects of accessibility were measured in this study including the provision of mobile applications and the ability to access and perform e-Government transactions 24 hours/7 days [21]. Spearman's correlation procedure was utilised to assess the correlation between ACC and PER. The result showed that the hypothesised positive relationship between Accessibility and Perceived E-Readiness was not supported, $\mathrm{r}_{\mathrm{s}}=-.198, \mathrm{n}=48, p>.05$. The test also showed no significant relationship between them. This indicates that 


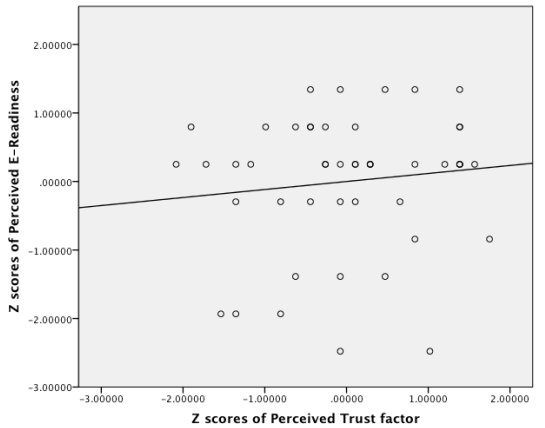

Fig. 9: The relationship between PT factor and PER.

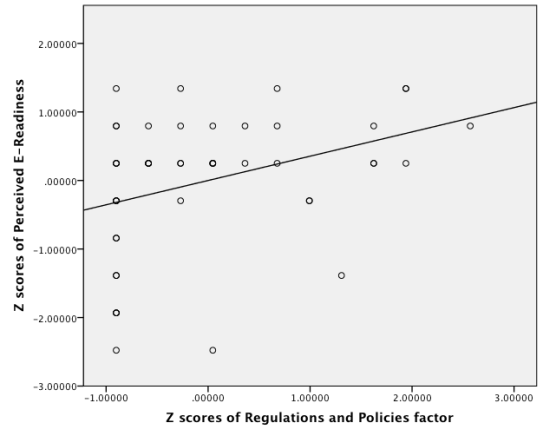

Fig. 10: The relationship between RP factor and PER.
Accessibility factor do not positively influence the e-Readiness perception of users from business sector.

H8: There would be a positive relationship between accessibility and perceived e-Readiness of e-Government.

This is likely because the majority of the participating business entities (66\%) were old companies that had been established before the e-Government initiative was introduced to Saudi Arabia [21]. Such old companies might still have negative views from performing governmental transactions using the traditional ways and thus, they believed that governmental agencies would not be able to provide sophisticated features that are related to e-Government accessibility such as e-Government support offices, mobile applications and also the ability to perform e-Services 24 hours/7 days a week.

\section{Perceived Trust (PT)}

This factor was measured with nine items and the single composite score has been computed for them, $M=2.34$ [21]. The Spearman's correlation test was performed between $P T$ and $P E R$ to explore the possible positive relationship between them which was proposed in EGAUM. Similar to $P S, T Q S$ and $A C C$ factors, there was a weak positive relationship between $P T$ and PER, $\mathrm{r}_{\mathrm{s}}=.097, \mathrm{n}=48, \mathrm{p}>.05$. Nevertheless, the hypothesised positive relationship was supported and its trend line can be seen in the scatterplot graph presented in Fig. 9.

H9: There would be a positive relationship between perceived trust and perceived e-Readiness of e-Government.

This insignificant impact of $P T$ was also indicated from the descriptive analysis of this factor [21]. This weak influence is likely because the majority of the participants in this sample were employees (72\%) and they possibly do not pay a lot of attention on trust issues as owners. Performing eGovernment transactions and services are considered to be their job activities and trust aspects would not affect their eReadiness perception or their intention to use.

Perceived Trust factor, which include perceived security and perceived privacy, is crucial factor when it comes to use virtual systems such as e-Government. Being able to place trust in a system is critical to consumers' successful interaction with that system [35]. Several research in the literature found that Perceived Trust is a significant factor that influence the adoption and intention to use e-Government [36][37][38][39]. However, the significance influence of $P T$ in these studies was reported from different e-Government stakeholders. The
Perceived Trust factor might not be a significant factor for users from business sector. As stated earlier that the majority participants were employees and the trust perception is likely not influencing their adoption and utilisation. This does not mean that the data that they provide online when performing e-Services is not important to them or they are careless about it, but the influence of trust is a degree matter and its influence differs from users group to another.

\section{Regulations and Policies (RP)}

Regulations and policies factor (RP) was measured with four items and a single composite score has been produced for correlation test. The relationship between $R P$ and $P E R$ was assessed utilising Spearman's procedure and the result showed a positive correlation between both variables. This relationship was statistically significant as the test showed, $\mathrm{r}_{\mathrm{s}}=.402, \mathrm{n}=48$, $p<.05$. Thus, the hypothesised relationship between $R P$ and $P E R$ was supported and the relationship trend line is presented in Fig. 10.

H10: There would be a positive relationship between regulations \& policies and perceived e-Readiness of e-Government.

The descriptive analysis of this factor also indicated a strong influence of $R P$ factor [21]. This means that the implemented regulations and policies for using e-Government services is likely to have significant influence on the adoption and utilisation of e-Government and its e-Readiness perception. The findings showed how implementing visible, strict and clear regulations and policies are important to users from business sector. This indicates that such users are eager to have such legislative and control perspective when using online governmental services and this is likely because conflicts and regulatory violation would cause negative impact on their business.

Moreover, the existence of clear regulations and laws for both parties' rights (business users and government agency) and making them available and visible to the users is crucial. This importance would be more emphasised when large business entities, like the participating entities, are using such online governmental systems. E-Government environment requires a comprehensive set of regulations, terms, conditions and laws that need to be applied by the e-Services providers to allow them to leverage the full potential of automation and online services provision while ensuring users perception, privacy and security [40]. Regulations and policies related to the use of e-Government systems are needed to create a 
favourable environment for promoting trusted governmental services over the Internet. Additionally, these regulations and policies are required to be updated regularly to encourage users to read and follow them.

\section{THEORETICAL CONTRIBUTIONS AND PRACTICAL IMPLICATIONS}

This study examined the adoption of e-Government services by potential users from business sector in Saudi Arabia. The contribution of this paper is twofold. First, guided by number of technology acceptance theories and models, the study develops an integrated theoretical model to investigate users' intention to adopt e-Government services from the business sector perspective. The new research model (EGAUM), was developed based on critical evaluation of such models and theories including TAM and UTAUT, in conjunction with analysis of technology acceptance literature [9]. It provides insight into number of crucial factors and determinants of higher adoption and use level. Second, the current study empirically validates this integrated model by analysing data that has been collected from targeted respondents and from different places. Eight of the 9 hypotheses specified in the model were supported. The results attest to the value of this research model.

The current study also informs practice. We briefly discuss the major implications derived from our research hypotheses in the following discussion. Perceived Benefits was found to be a direct influential factor on the intentions to use e-Government services. Users who have higher perceptions of e-Government benefits are more likely to adopt and use its services and transactions. Their intention to use e-Government services is very likely to increase if they perceive the e-Services to be beneficial for their businesses. Such e-Services should be implemented efficiently and effectively in order to meet the needs of this category of stakeholders. Government agencies should disseminate the benefits and advantages of using such online services and also present the potentials of implementing such e-Services. Moreover, they should play a proactive role in popularizing the benefits of online government e-Services to the users from business sector.

Furthermore, Awareness was also found to be a significant factor that is likely to increase the intention to adopt and use. If users from the business sector are informed about the existing e-Services and their potentials and benefits, they are likely to appreciate e-Government services and thus, they would be encouraged to adopt them and use them. Providing eServices without their users' knowledge or without promoting the awareness of their benefits and potentials would limit achieving the goals of implementing e-Government. Different methods were found to be significant in terms of increasing the awareness of users from business sector. For example, Social media found to be very influential method that would increase users' willingness to use e-Government services for their business. Albayari stated that social media revolutionised the business sector in Saudi Arabia since it creates sufficient ways to communicate with customers [41]. This indicates that most of business entities have accounts in social media networks and also new businesses are expected to follow the same trend of using social media. The result of this study and the status of social media spread in business sector in Saudi provide government with an excellent way of marketing eGovernment services and increase the awareness about their benefits and potentials.

We anticipated that the previous experience of online activities would have an impact on the future adoption and use of e-Government services. The results found that the past use of e-Government services would influence users' intention to use such online services repeatedly. Moreover, the past use of non-governmental online services was also found to be an influential factor. Generally, the online activities that involve transactions and services are still new trend in Saudi Arabia. The study results alert the e-Services providers to enhance users experience. This should be considered from the first introduction of e-Services. Furthermore, improving the ICTs infrastructure would be positively reflected on the online activities.

The implemented regulations and policies also found to be a significant factor that influences users' adoption and use. The results revealed that implementing regulations, policies, conditions and terms of using e-Government systems is very important to users from business sector. They should be implemented properly by making them clear, strict, applicable to all parties (users, employees and agencies), accessible, comprehensive and visible. Formulating rules, policies, terms and conditions of using e-Government systems is not the only main thing, but also providing them in a way that encourage users to read and understand them would increase their confidence which in turn increase their adoption and use. This would also help to control such online dealings especially with business sector that contributes to the country's economy

\section{CONCLUSION}

The current study attempts to understand users' intention to adopt and utilise e-Government services from the business sector perspective in Saudi Arabia. The adoption and utilisation of e-Government considered to be a challenge, and therefore, an interesting research area is introduced. We developed a research model (EGAUM) under the umbrella of different scientific theories and models that are related to technology acceptance and use. We empirically tested the proposed model by analysing data collected from targeted sample. The results of the this study revealed that PB, AW, PE and RP found to be significant factors that influence the adoption and utilisation of e-Government services provided to business sector in Saudi Arabia. Although there are some limitations in this study such as the majority of male participants and the majority of large participating business firms, this study provides useful insights into the motivations underlying the intentions to adopt and use e-Government services from the business sector perspective in developing countries like Saudi Arabia.

\section{REFERENCES}

[1] R. Davidrajuh, Planning e-government start-up: a case study on e-Sri Lanka. Electronic Government: An International Journal, Volume 1, No 1, pp. 92-106, 2004.

[2] S. Alshafi, and V. Weerakkody, "Factors affecting e-government adoption in the state of Qatar". Proceedings of the European and Mediterranean Conference on Information Systems, Abu Dhabi, UAE, 2010.

[3] S. Archmann, and J. Castillo Iglesias, "eGovernment: A Driving Force for Innovation and Efficiency in Public Administration". EIPAScope, 2010 (1). pp. 29-36. 
[4] T. Gebba, and M.R. Zakaria, "E-Government in Egypt: An Analysis of Practices and Challenges". International Journal of Technology and Management. Vol. 1 No. 1, pp. 11-25, 2012.

[5] E. Ziemba, T. Papaj, and R. Zelazny, "A Model of Success Factors for E-government Adoption - The Case of Poland". Journal of Computer Information Systems, Vol. 14, Issue 2, pp. 87-100, 2013.

[6] S. AlAwadhi, and A. Morris, "Factors influencing the adoption of egovernment services". Journal of Software, 4(6), pp.584-590, 2009.

[7] M. Kunstelj, T. Jukic, and M. Vintar, "Analysing the Demand Side of EGovernment: What Can We Learn From Slovenian Users?". Electronic Government Lecture Notes in Computer Science, Vol.4656, pp 305-317, 2007. DOI:10.1007978-3-540-74444-3 26.

[8] Research and Economic Reports Unit 2015 [Growing rate of private sector in the Kingdom of Saudi Arabia]. Al-Jazirah [Online] Available from: http://www.al-jazirah.com (accessed in 28/04/2015) (In Arabic).

[9] S. Alghamdi, and N. Beloff, "Towards a Comprehensive Model for E Government Adoption and Utilisation Analysis: The Case of Saudi Arabia". Federated Conference on Computer Science and Information Systems, ACSIS, Vol. 2, pp. 1217-1225, 2014. DOI: 10.15439/2014F146.

[10] I. Ajzen, and M. Fishbein, "Belief, attitude, intention, and behaviour: An introduction to theory and research". Reading, MA: Addison-Wesley, 1975

[11] D. Davis, P. Bagozzi, and R. Warshaw, "User Acceptance of Computer Technology: A Comparison of Two Theoretical Models". Management Science, Vol. 35, No. 8, 1989

[12] E. Rogers, Diffusion of Innovations. The Free Press, New York, USA, 1995.

[13] G. Moore, and I. Benbasat, "Development of an instrument to measure the perceptions of adopting an information technology innovation". Information Systems Research, Vol. 2 Issue 3, pp192, 1991. DOI 10.1287/isre.2.3.192

[14] V. Venkatesh, M. Morris, G. Davis, and F. Davis, "User Acceptance of Information Technology: Toward a Unified View". Management Information Systems Quarterly, Vol. 27, Issue.3, 2003.

[15] J. Raubenheimer, "An Item Selection Procedure to Maximise Scale Reliability and Validity". SA Journal of Industrial Psychology, 30 (4), 59-64, 2004.

[16] N. Blunch, "Introduction to Structural Equation Modelling Using IBM SPSS Statistics and AMOS". Second Edition, SAGE publication Ltd, p.p. $31-50,2013$

[17] D.K. Bhattacharyya, Cross-cultural Management: Texts and Cases. PHI learning private limited, New Delhi, p.p.317-319, 2010

[18] D. Colton, and R.W. Covert, "Designing and Constructing Instruments for Social Research and Evaluation". Jossey-Bass, Wiley Imprint, San Francisco, p.p. 64-74, 2007.

[19] B.R Worthen, W.R. Borg, and K.R. White, "Measurement and evaluation in the schools". New York: Longman, 1993.

[20] B. Nevo, "Face validity revisited". Journal of Educational Measurement, 22, pp. 287-293, 1985

[21] S. Alghamdi, and N. Beloff, "Exploring determinants of adoption and higher utilisation for e-Government: A study from business sector perspective in Saudi Arabia". Computer Science and Information Systems conference (FedCSIS), ACSIS, Vol. 5, pp. 1469 - 1479, 2015. DOI: $10.15439 / 2015 \mathrm{~F} 257$

[22] L. Carter, and F. Belanger, "Citizen adoption of electronic government initiatives", 37th Hawaii International Conference on System Sciences, Hawaii, 2004.

[23] D.V. Dimitrova, and Y.C.Chen, "Profiling the adopters of e-government information and services: the influence of psychological characteristics", civic mindedness, and information channels. Social Science Computer Review,(24:2), pp.172-188, 2006.

[24] Rogers, E. (1995). Diffusion of innovations (4th ed.). New York: Free Press

[25] S. AlAwadi, and A. Morris, "Factors Influencing the Adoption of Egovernment Services". Journal of Software, Vol.4, No.6, pp. 584-590, 2009
[26] M. Alshehri, S. Drew, and R. Alghamdi, "Analysis of Citizens' Acceptance for E-Government Services: Applying the UTAUT model". IADIS International Conferences Theory and Practice in Modern Computing and Internet Applications and Research, 2012.

[27] H. AlShihi, "E-government development and adoption dilemma: Oman case study", 6th International We-B (Working for e-Business) Conference, Victoria University, Melbourne, Australia, 2005.

[28] P. M. A. Baker, and C. Bellordre, "Adoption of information and communication technologies: key policy issues, barriers and opportunities for people with disabilities". 37th Hawaii International Conference on System Sciences, 2004, Hawaii.

[29] A. Savoldelli, C. Codagnone, And G. Misuraca, "Understanding the e-government paradox: Learning from literature and practice on barriers to adoption". Government Information Quarterly, Volume 31, Supplement 1, June 2014, Pages S63-S71, 2014, ISSN 0740-624X, http://dx.doi.org/10.1016/j.giq.2014.01.008.

[30] H.M. Abdelsalam, C.G. Reddick, and H.A. El Kadi, "Success and Failure of Local E-Government Projects: Lessons Learned from Egypt". In S. Aikins (Ed.), Managing E-Government Projects: Concepts, Issues, and Best Practices, pp. 242-261, 2012. Hershey, PA: Information Science Reference. doi:10.4018/978-1-4666-0086-7.ch010projects. Dig Democr: Conc, Method, Tools, Appl 2012;vol. 3:183.

[31] H. Elkadi, "Success and failure factors for e-government projects: A case from Egypt". Egyptian Informatics Journal, Volume 14, Issue 2, July 2013, Pages 165-173, ISSN 1110-8665, http://dx.doi.org/10.1016/j.eij.2013.06.002.

[32] M, Rehman, V. Esichaikul, and M. Kamal, "Factors influencing egovernment adoption in Pakistan". Transforming Government: People, Process and Policy, Vol. 6 No. 3, pp. 258-282, 2010. DOI: $10.1108 / 17506161211251263$

[33] E. Ziemba, T. Papaj, and D. Descours, "Assessing the quality of egovernment portals - the Polish experience". Federated Conference on Computer Science and Information Systems, ACSIS. Vol.2, pp.12591267, 2014. DOI: $10.15439 / 2014 \mathrm{~F} 121$

[34] M. Alshehri, S. Drew, T. Alhussain, and R. Alghamdi, "The Effects of Website Quality on Adoption of E-Government Service: An Empirical Study Applying UTAUT Model Using SEM". Proceedings of the 23rd Australasian Conference On Information Systems (ACIS 2012), p.p. 1 $-13,2012$.

[35] D. Gefen, E. Karahanna, and D.W. Straub, "Trust and TAM in online shopping: An integrated model". MIS Quarterly, 27, pp. 51-90, 2003.

[36] M. Shareef, V. Kumar, U. Kumar, and Y. Dwivedi, "e-Government Adoption Model (GAM): Differing service maturity levels". Government Information Quarterly 28, p.p, 2011. 17-35.

[37] M. Warkentin, D. Gefen, P. Pavlou, and G. Rose, "Encouraging citizen adoption of e-government by building trust". Electronic Markets, 12(3), pp. 157-162, 2002.

[38] L. Carter, and F. Belanger, "The utilization of e-government services: citizen trust, innovation and acceptance factors". Information Systems journal, 15, p.p. 5-25, 2005.

[39] V. Weerakoddy, R. El-Haddadeh, F. Al-Sobhi, M. Shareef, and Y. Dwivedi, "Examining the influence of intermediaries in facilitating egovernment adoption: An empirical investigation". International Journal of Information Management, 33, p.p. 716-725, 2013.

[40] R. Barnnat, A. Johnstone-Burt, W. Zink, and F. Thome, "EGovernment Ten Lessons Learned from the Best Global Programs", 2010. Booz \& Company. [Online] Available from: http://www.strategyand.pwc.com/media/file/e-government.pdf (accessed in $16 / 06 / 15)$

[41] KH. H. Albayari, "Social Media Websites Create Revolution in Business Sector", 2011. Alriyadh newspaper. [Online] Available from: http://www.alriyadh.com/674523.

[42] J.W. Cohen, (1988) Statistical power analysis for the behavioural science (2nd ed). Hillsdale, NJ: Lawrence Erlbaum Associates. 